This PDF is a selection from an out-of-print volume from the National Bureau of Economic Research

Volume Title: Frontiers in Health Policy Research, volume 1

Volume Author/Editor: Alan M. Garber, editor

Volume Publisher: MIT

Volume ISBN: 0-262-57120-X

Volume URL: http://www.nber.org/books/garb98-1

Publication Date: January 1998

Chapter Title: Managed Care and Health Care Expenditures: Evidence from Medicare, 1990 to 1994

Chapter Author: Laurence C. Baker, Sharmila Shankarkumar

Chapter URL: http://www.nber.org/chapters/c9825

Chapter pages in book: (p. 117 -152) 


\title{
Managed Care and Health Care Expenditures: Evidence from Medicare, 1990-1994
}

\author{
Laurence C. Baker, Stanford University and NBER \\ Sharmila Shankarkumar, Stanford University
}

\section{Executive Summary}

Increases in the activity of managed care organizations may have "spillover effects," influencing the entire health care delivery system's performance, so that care for both managed-care and non-managed-care patients is affected. Some proposals for Medicare reform have incorporated spillover effects as a way that increasing Medicare HMO enrollment could contribute to savings for Medicare.

This paper investigates the relationship between $\mathrm{HMO}$ market share and expenditures for the care of beneficiaries enrolled in traditional fee-for-service Medicare. We find that increases in systemwide HMO market share (which includes both Medicare and non-Medicare enrollment) are associated with declines in both Part A and Part B fee-for-service expenditures. The fact that managed care can influence expenditures for this population, which should be well insulated from the direct effects of managed care, suggests that managedcare activity can have broad effects on the entire health care market. Increases in Medicare HMO market share alone are associated with increases in Part A expenditures and with small decreases in Part B expenditures. This suggests that any spillovers directly associated with Medicare HMO enrollment are small.

For general health care policy discussions, these results suggest that assessment of new policies that would influence managed care should account not only for its effects on enrollees but also for its systemwide effects. For Medicare policy discussions, these findings imply that previous results that seemed to show large spillover effects associated with increases in Medicare HMO market share, but inadequately accounted for systemwide managed-care activity and relied on older data, overstated the magnitude of actual Medicare spillovers.

We thank David Cutler, Alan Garber, and Mark McClellan for helpful suggestions regarding this research. Address correspondence to Laurence Baker, Department of Health Research and Policy, HRP Redwood Building, Rm 253, Stanford University School of Medicine, Stanford, CA 94305-5405 


\section{Introduction}

As managed care's influence grows, understanding its influence on the structure and functioning of the health care marketplace is increasingly important. During recent years, a number of studies have examined the hypothesis that managed-care activity may broadly affect the entire health care system through so-called spillover effects. These studies argue that managed-care organizations may, among other things, compete with non-managed-care providers or insurers, influence the systemwide availability of new technologies or other health care services, influence the structure of hospital markets, and contribute to the spread of conservative practice patterns among non-managed-care providers, all of which contribute to changes in provider behavior and health care costs throughout the health care system.

Whether managed care can have widespread effects on health care delivery and costs is important for assessing the effects of the health care system's ongoing transformation on health care costs and patient care and for evaluating policies that would encourage or discourage growth in managed care. In particular, most analyses of managed care have focused on patients enrolled in managed care plans, but the presence of spillover effects would imply the need to include consideration of non-managed-care enrollees as well.

This chapter investigates the relationship between systemwide managed care activity and expenditures for the care of patients covered by Medicare's traditional fee-for-service (FFS) plan. These patients should be well insulated from managed care's direct effects, so that studying their expenditures provides a strong test of managed care's ability to influence care for non-managed-care patients. FFS Medicare is a welldefined, stable insurance plan that does not subject patients to the limitations managed care plans typically impose. There is little or no central management of provider or patient utilization choices (i.e., utilization review). It imposes no strong financial incentives on providers to limit utilization. Physicians caring for Medicare FFS patients are paid on a fee-for-service basis, subject only to limitations on the fees for individual services embodied in the Medicare Fee Schedule. Hospitals are paid using diagnosis-related groups (DRGs). Although DRGs do impose some incentives for cost containment, they are among the weaker incentives used to influence hospitals in today's health care system and, in fact, some work has shown that DRGs do vary with treatment intensity, so that the incentive for hospitals to reduce intensity to contain costs is not complete (McClellan 1997). In addition, the 
Medicare FFS program does not compete for patients, and the competitive forces that increasingly pervade the overall health care system therefore do not influence it. Overall, because FFS Medicare patients should be well outside the boundaries of managed care, any effect of managed care on their expenditures may be taken as clear evidence of managed care's power to transform the health care system fundamentally in ways that affect all patients.

Focusing on Medicare expenditures also allows us to investigate issues related to Medicare policy. Spillover effects that affect Medicare spending have attracted particular interest in Medicare reform discussions because policy changes that would increase HMO enrollment among Medicare beneficiaries could produce spillovers, reducing Medicare costs and contributing to the savings needed to restore balance in Medicare financing. The key question is whether changes in Medicare HMO activity can themselves bring about savings through spillover effects. Although most examinations of spillover effects focus on managed-care activity throughout the health care system, the existence of expenditure-reducing spillover effects induced by HMO activity outside of Medicare need not imply that changes in Medicare HMO activity also produce savings. Existing studies that look specifically at Medicare HMO market share have not fully answered this question, because they have not clearly identified the effects of Medicare HMO enrollment separately from systemwide HMO effects. This chapter studies Medicare HMO market share's effect on expenditures, controlling for changes in systemwide HMO activity.

A number of previous studies have examined spillover effects from various perspectives (e.g., Goldberg and Greenberg 1979; Frank and Welch 1985; Feldman et al. 1986; Luft et al. 1986; Dowd 1987; McLaughlin 1987, 1988; Noether 1988; Robinson 1991, 1996; Baker 1994; Chernew 1995; Baker and Corts 1996). Although these studies contribute to our understanding of spillover effects, data limitations have left them generally unable to draw clear, broad-based conclusions about systemwide managed-care activity's impact on non-managed-care patients. Some of these studies have been forced to rely on data about managed care from only a small number of markets. Many have also had to rely on expenditure data from single sectors of the health care market (e.g., only from hospitals), which makes generalization difficult, or have had to lump together spending by managed-care and non-managed-care patients, which makes it difficult to separate spillover effects from managed care organizations' effects on the care provided to enrollees. This chapter uses detailed nationwide data on 
HMO market share along with ambulatory and hospital expenditures for a well-defined group of FFS patients to overcome these difficulties.

Four studies have examined Medicare data for evidence of spillovers. Baker (1997) examined data on Medicare HMO enrollment and FFS expenditures between 1986 and 1990, finding that increases in Medicare market share from 10 to $20 \%$ were associated with decreases of 4.5 and $4.1 \%$ in FFS expenditures for hospital and physician services, respectively. Welch (1994) found a negative relationship between Medicare risk HMO market share and aggregate (HMO and nonHMO) Medicare expenditures per beneficiary between 1984 and 1987. Clement, Gleason, and Brown (1992) used data from 1985-88 and estimated that increases of ten percentage points in Medicare risk HMO market share were associated with $5 \%$ decreases in Medicare FFS expenditures, although the results were sensitive to specification. Finally, Rodgers and Smith (1995) reported that increases in Medicare risk HMO market share were associated with decreases in FFS expenditures between 1988 and 1992. Although these studies offer insights into the existence of spillover effects in general, their main shortcoming is that they tend to focus only on Medicare HMO market share ${ }^{1}$ and have been unable to clearly distinguish Medicare-specific spillovers from systemwide spillovers. Nonetheless, some have interpreted their results to imply that increases in Medicare HMO market share would lead to declines in Medicare FFS spending (e.g., Rodgers and Smith 1995; Hammonds 1997). In this chapter, we include both systemwide and Medicare-specific HMO market share to disentangle these two effects and evaluate this conclusion.

The remainder of this chapter proceeds as follows. The next section discusses how managed care may be expected to influence expenditures and the issues raised when examining managed-care spillovers in Medicare. Section III discusses estimation issues and presents results, and section IV concludes.

\section{HMOs and Health Care Expenditures}

\section{Mechanisms}

The term "managed care," in popular parlance, is often poorly defined and can refer to a wide variety of health care organizations. In this 
chapter, we use this term to refer conceptually to organizations that take an active role in limiting the providers their patients can use (e.g., through selective contracting), that use financial incentives designed to limit utilization (e.g., capitation), and/or that actively limit patient utilization through other means (e.g., utilization review). This is a purposefully broad set of criteria designed to capture the spirit of recent changes in the health care marketplace. Although this framework guides conceptual development, practical considerations constrain the empirical work described below to focus only on HMOs.

Managed care may influence FFS expenditures through a variety of mechanisms. First, increases in managed-care activity may change the health care delivery system's structure and capacity. For example, managed care may change the incentives associated with the purchase of high-cost medical technologies, affecting technology availability in markets (Baker and Wheeler 1997; Cutler and Sheiner 1997). Similar effects could result if managed care changes the structure of the hospital market, the size or behavior of individual hospitals (e.g., Chernew 1995), the number and type of health care providers (Baker and Brown 1997), or other market characteristics. By changing the environment in which medicine is practiced, managed care may influence the type and costs of care provided to all patients.

Managed care may also influence health care providers' behavior, independent of any effects it may have on the overall availability of services. For example, in markets with high levels of managed-care activity, all providers may be less likely to use procedures perceived to have high ratios of costs to benefits. This could occur through a variety of mechanisms. If, as some models of physician learning suggest (e.g., Phelps 1992), physicians tend to adopt the practice patterns of other physicians around them, increases in the number of managedcare physicians practicing in a given area may result in faster promulgation of conservative practice techniques. A related possibility is that physicians who see both managed care and FFS patients may adopt more conservative practice styles throughout their practices. Finally, increases in managed-care activity or other increases in the strength of managed-care organization vis-à-vis traditional providers and insurers may increase competitive pressure as non-managed-care providers and insurers compete with managed-care organizations for the business of employers and patients. Competition could force nonmanaged-care providers to change how they provide care or prompt insurers to expand utilization review and other oversight efforts, leading to changes in utilization. (It should be noted that competition could 
also be associated with increasing expenditures. For example, competition from managed-care plans may prompt FFS providers to compete on the basis of quality or technology. $\mathrm{O}_{\boldsymbol{\gamma}}$, if managed care pulls patients away from physicians, they may respond by inducing demand from or increasing charges to non-managed-care patients. ${ }^{2}$ )

A final mechanism by which managed-care activity could have spillover effects on FFS expenditures is price. If non-managed-care providers or insurers earn excess profits in the absence of managed care, increasing competition could enhance market discipline and lead to lower prices.

\section{Observing Spillover Effects in Medicare Data}

The Medicare program provides an excellent opportunity to observe many of the effects described above. In particular, changes in the health care system's structure and capacity and changes in utilization patterns should influence Medicare expenditures. Most health care providers and most hospitals care for both Medicare and non-Medicare patients. If, for example, managed-care activity reduces the number of MRI machines available in a market, then utilization of MRI for Medicare patients is likely to be influenced. Similarly, if providers adopt more conservative practice styles for their non-Medicare patients, Medicare FFS patients may also be treated more conservatively. Because Part $B$ reimbursement is based on the number and type of procedures performed, Part B expenditures will vary with changes in utilization. Part A expenditures capture variation in the number of hospitalizations and some variation in in-hospital utilization, although the Prospective Payment System, which governs Part A payments, dampens the relationship between in-hospital utilization intensity and Part A expenditures. ${ }^{3}$

A word on the role of competition is important here. Although competition-driven changes in technology availability or utilization could easily influence the care Medicare beneficiaries receive, these

2. Physicians' willingness and ability to do this is a subject of debate. Some evidence (e.g., Mitchell, Wedig, and Cromwell 1989; Cromwell and Mitchell 1986) indicates that physicians can induce demand and may do so in response to reductions in demand or prices.

3. Note, however, that McClellan (1997) shows that substantial portions of the variance in hospital reimbursements under the prospective payment system can be explained by variation in procedure codes and outlier payments that reflect variation in utilization patterns, so that Part A expenditures reflect in-hospital intensity to at least some degree. 
competitive effects are likely to arise from non-Medicare sectors of the health care market since competition for Medicare beneficiaries is unlikely to have a strong impact on behavior. Medicare does not compete for the business of the elderly and disabled and does not operate under the same incentives that face for-profit insurance companies and health care providers (Clement, Gleason, and Brown 1992). In addition, provider behavior with respect to pricing and utilization has only small effects on the prices that Medicare FFS beneficiaries pay for coverage and care.

Although utilization effects should show up in the Medicare data, the structure Medicare imposes on the payments made to physicians and hospitals severely limits the extent to which managed careinduced price changes can occur in Medicare. Since 1983, the Health Care Financing Administration (HCFA) has reimbursed hospitals using the Prospective Payment System, which significantly limits managed care-induced price variation in Part A expenditures. Similarly, in the early 1990s, HCFA began phasing in the Medicare Fee Schedule for reimbursement of physicians under Part B. This schedule limits managed care-induced variation in physician prices. Since the fee schedule was being phased in during the time period on which we focus, all data presented here are adjusted to reflect what payments would have been under the 1994 fee schedule, which further limits the effect that changes in prices over time could have on our data. However, it remains theoretically possible that price effects could appear in our data to the extent that managed care-induced changes in physician or hospital prices were incorporated into the Prospective Payment System or fee schedule payment rates, although we believe this effect is relatively weak.

\section{Systemwide Spillovers versus Medicare-Specific Spillovers}

For discussions of Medicare policy, it is important to distinguish between the effects of systemwide and Medicare-specific managed care activity. "Systemwide" managed-care activity includes changes in the size, market power, or other aspects of managed-care organizations' behavior throughout the health care system, possibly including the effects of increasing managed-care activity within Medicare. "Medicare-specific" managed-care activity captures changes in the enrollment in only the Medicare portion of managed-care organizations. Changes in expenditures induced by Medicare-specific managed-care 
activity occur because only Medicare managed-care activity changed, independent of any other changes in the managed-care market. Changes in systemwide managed care activity induce expenditure effects because the entire sector's influence has changed.

If spillovers occur because managed-care activity changes throughout the entire health care system, then changes in Medicare HMO enrollment that Medicare policy changes might bring about would produce spillover effects only to the extent that increases in Medicare HMO enrollment increase overall enrollment. Because Medicare enrollment is only a fraction of overall enrollment, this would limit the impact increases in Medicare enrollment could have through spillovers. On the other hand, if increases in Medicare HMO market share itself directly influences expenditures independent of systemwide changes in market share, savings obtained could be greater.

It is not clear that the effects of systemwide and Medicare-specific HMO market share should be the same. Systemwide changes in managed-care activity have broad latitude in how they influence expenditures. In fact, all of the spillover effect mechanisms identified above could plausibly begin with systemwide managed care changes. On the other hand, Medicare-specific spillovers have much more limited potential to have strong effects (Clement, Gleason, and Brown 1992; Baker 1997). There is little reason to believe that Medicare-specific activity would bring about large changes in the overall health care market's structure and capacity or have important competitive effects. Significant Medicare-specific effects could occur most plausibly through learning and related effects. For example, if providers who see elderly or disabled patients share information among themselves but not with other physicians more generally, then increases in Medicare managedcare activity could change the behavior of Medicare FFS providers independent of changes in the non-Medicare market.

Although understanding Medicare-specific spillover effects is crucial for Medicare policy, it is difficult to draw conclusions about the size of Medicare-specific spillover effects from previous work. Because systemwide and Medicare-specific spillovers need not be the same, inferences cannot reliably be drawn from studies of spillover effects outside of Medicare. Although some studies have examined the effects of Medicare HMO market share on expenditures (Baker 1997; Welch 1994; Clement, Gleason, and Brown 1992; Rodgers and Smith 1995), they have not typically included systemwide HMO activity. Since systemwide managed-care activity and Medicare HMO activity are 
correlated, the relationship between HMO market share and expenditures could capture the effects of both Medicare-specific and systemwide managed-care activity. One goal of this chapter is to apply new data to attempt to disentangle these effects.

\section{Data}

\section{Medicare Expenditures}

Data on Part A and Part B Medicare FFS expenditures and enrollment by county for all counties in the United States for 1990-94 were obtained from HCFA. The expenditure data include only expenditures made on behalf of FFS beneficiaries ${ }^{4}$-payments to HMOs and other providers for the care of HMO-enrolled beneficiaries are not included. The data also exclude expenditures Medicare does not cover, such as copayments, deductibles, payments made for services not covered by Medicare, and payments for services covered by Medigap insurance. To construct the county-level measures of spending, expenditures for each beneficiary are assigned to his or her county of residence, regardless of where the expenditures were incurred.

The Medicare Fee Schedule governing Medicare payments to physicians was phased in during the time period under study here. To ensure that this does not affect the findings, the HCFA Office of the Actuary has adjusted the data for each year to reflect what payments in each year would have been under the 1994 Medicare Fee Schedule. This adjustment virtually eliminates the (already small) possibility of observing managed care-induced changes in physician prices.

For our analyses, we aggregate the county-level data to produce measures of spending for Health Care Service Areas (HCSAs): groups of counties thought to approximate markets for health services (Makuc et al. 1991). There are 802 HCSAs in the United States, representing both urban and rural areas. We expect HCSAs to be superior to counties as a market definition, because many counties are too small to represent adequately markets for health care services.

Table 4.1 reports national average expenditures per beneficiary for 1990-94. In 1990, on average, Medicare spent $\$ 2,037$ per beneficiary for

4. The sample includes expenditures for the elderly and disabled but excludes expenditures for patients with end-stage renal disease, who are also covered by Medicare but make up less than $1 \%$ of beneficiaries and tend to have distinct health needs. 
Table 4.1

Mean nominal Medicare FFS expenditures per beneficiary, 1990-1994

\begin{tabular}{lllll}
\hline Year & Part A & $\begin{array}{l}\text { \% change from } \\
\text { previous year }\end{array}$ & Part B & $\begin{array}{l}\text { \% change from } \\
\text { previous year }\end{array}$ \\
\hline 1990 & $\begin{array}{l}\$ 2,037 \\
(574)\end{array}$ & - & $\begin{array}{l}\$ 1,233 \\
(346)\end{array}$ & - \\
1991 & $\begin{array}{l}\$ 2,152 \\
(547)\end{array}$ & $5.6 \%$ & $\begin{array}{l}\$ 1,273 \\
(338)\end{array}$ & $3.2 \%$ \\
1992 & $\begin{array}{l}\$ 2,432 \\
(557)\end{array}$ & $13.0 \%$ & $\begin{array}{l}\$ 1,322 \\
(324)\end{array}$ & $3.8 \%$ \\
1993 & $\begin{array}{l}\$ 2,616 \\
(645)\end{array}$ & $7.6 \%$ & $\begin{array}{l}\$ 1,397 \\
(367)\end{array}$ & $5.7 \%$ \\
1994 & $\begin{array}{l}\$ 2,865 \\
(701)\end{array}$ & $9.5 \%$ & $\begin{array}{l}\$ 1,539 \\
(361)\end{array}$ & $10.2 \%$ \\
\% change 1990-94 & & $40.6 \%$ & $24.8 \%$ \\
\hline
\end{tabular}

Note: Standard errors in parentheses. Values shown are national averages.

Part A services and \$1,233 per beneficiary for Part B services. By 1994, these amounts had risen to $\$ 2,865$ and $\$ 1,539$, increases of $40.6 \%$ and $24.8 \%$, respectively.

\section{Medicare HMO Market Shares}

Although the arguments developed above apply to managed care broadly, we focus our analytical efforts on HMO market share. This follows previous work and is, in practice, the only variable for which we can obtain comparable data over time for relatively small geographic areas. County-level data on the number of Medicare Part A beneficiaries enrolled in HMOs for 1989-94 (including risk, cost, and HCPPs) were obtained from HCFA. ${ }^{5}$ County-level HMO market shares are simply the ratio of the number of HMO enrollees to the number of beneficiaries in each county.

As above, we aggregate the county-level data to form measures of Medicare HMO market share for market areas. The top panel of table 4.2 presents summary statistics for area Medicare HMO market shares

5. Although some previous analyses have used only risk HMO enrollment, this does not capture HIMO activity as broadly or accurately as HMO market share from all contract types. Moreover, focusing only on risk enrollment may induce bias because Medicare HMOs can choose annually whether to operate as risk or cost plans, and FFS expenditure levels are likely to influence this choice. 
Table 4.2

Summary statistics for HMO market share measures

\begin{tabular}{|c|c|c|c|c|c|c|c|}
\hline \multirow[b]{2}{*}{ Year } & \multirow[b]{2}{*}{$\begin{array}{l}\text { Weighted } \\
\text { mean }\end{array}$} & \multicolumn{6}{|c|}{ Unweighted } \\
\hline & & Mean & $\begin{array}{l}\text { Standard } \\
\text { deviation }\end{array}$ & $\begin{array}{l}\text { 25th } \\
\text { percentile }\end{array}$ & Median & $\begin{array}{l}\text { 75th } \\
\text { percentile }\end{array}$ & $\begin{array}{l}\text { 90th } \\
\text { percentile }\end{array}$ \\
\hline \multicolumn{8}{|c|}{ Medicare HMO market share } \\
\hline 1990 & 6.4 & 2.3 & 5.4 & 0.1 & 0.3 & 1.5 & 6.8 \\
\hline 1991 & 5.7 & 2.1 & 4.8 & 0.1 & 0.3 & 1.4 & 5.6 \\
\hline 1992 & 6.0 & 2.2 & 5.0 & 0.2 & 0.3 & 1.5 & 5.9 \\
\hline 1993 & 6.8 & 2.4 & 5.6 & 0.2 & 0.4 & 1.5 & 6.6 \\
\hline 1994 & 7.8 & 2.8 & 6.2 & 0.2 & 0.4 & 2.0 & 7.7 \\
\hline \multicolumn{8}{|c|}{ Systemwide HMO market share } \\
\hline 1990 & 15.1 & 5.9 & 8.1 & 0 & 2.5 & 8.8 & 16.2 \\
\hline 1991 & 15.7 & 6.1 & 8.3 & 0 & 2.6 & 9.5 & 16.2 \\
\hline 1992 & 16.7 & 6.7 & 8.8 & 0.2 & 3.2 & 10.3 & 17.4 \\
\hline 1993 & 18.2 & 7.5 & 9.3 & 0.5 & 4.1 & 11.2 & 18.9 \\
\hline 1994 & 20.5 & 9.0 & 9.9 & 1.4 & 5.7 & 13.4 & 22.5 \\
\hline
\end{tabular}

Note: Sample size is 802 Health Care Services Areas per year. Weighted means reflect nationwide population averages-weighted Medicare market share measures are weighted by Medicare enrollment, and weighted systemwide market shares are weighted by county population.

by year. The first column presents means weighted by the number of Medicare beneficiaries in each market area to produce national averages. Between 1990 and 1994, mean Medicare HMO market share grew from $6.4 \%$ to $7.8 \%$. Since 1994, Medicare HMO market share has continued to grow, reaching approximately $10 \%$ in 1996.

Figure 4.1 graphs the distribution of 1994 levels and 1990-94 changes in Medicare market shares. 1994 market shares in the sample range from 0 to $47 \%$. Medicare market shares have a highly skewed distribution, as evidenced by the fact that the median market shares are all well below the means. Between 1990 and 1994, Medicare HMO market share changed little in most areas. Among market areas in the sample, 1990-94 changes ranged from $--9 \%$ to $+27 \%$. There was some upward movement in HMO market share in some areas, but most experienced only very small changes in market share. In this sample 1.0 percent $(N=8)$ had decreased of more than $5 \%, 4.2 \%(N=34)$ had increases of more than $5 \%$, and $81 \%(N=650)$ had changes that fell between $-1 \%$ and $+1 \%$. 


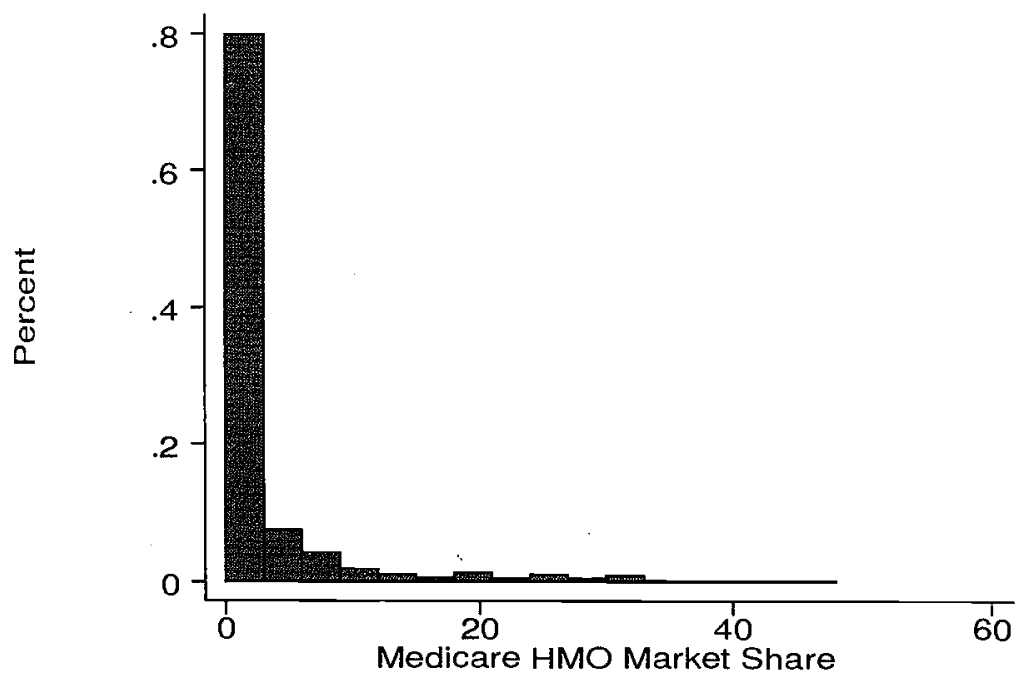

Figure 4.1a

Distribution of 1994 levels of Medicare HMO market share

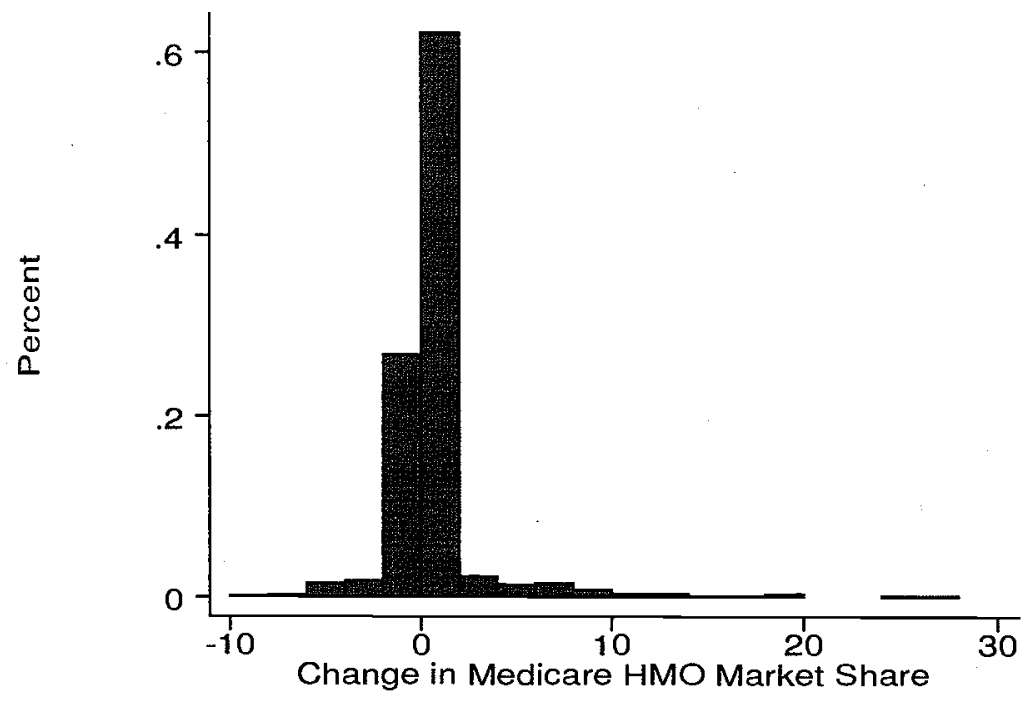

Figure 4.1b

1990-1994 changes in Medicare HMO market share

Note: Figures are based on 802 HCSAs each. Market areas are defined as HCSAs. 


\section{Systemwide HMO Market Shares}

In addition to Medicare HMO market shares, we also incorporate estimates of systemwide (Medicare and non-Medicare) HMO market share. These estimates were constructed for previous studies using data from the Group Health Association of America (now called the American Association of Health Plans). Conceptually, construction took place in three steps. First, the total enrollment and service area, specified by county, of each HMO in the United States were obtained from annual surveys conducted by the GHAA that asked all known HMOs in the country about their total enrollment, county service area, and headquarters location. The results of the survey were published in the annual National Directory of HMOs. ${ }^{6}$

Next, the enrollment of each $\mathrm{HMO}$ was distributed among the counties in its service area. Initially, enrollment was simply distributed proportionally to county population. In addition, because HMO enrollment may be concentrated near HMO headquarters or because HMOs may locate their headquarters in areas where their enrollment is concentrated, estimates that incorporate both county population and distance from HMO headquarters were constructed. Estimates produced by the two methods have a correlation of approximately 0.97 . Estimates that incorporate both population and distance were used in this study.

Finally, once enrollments had been distributed over service areas, the total number of enrollees in each county was computed by summing over the set of HMOs serving that county. Using the set of county enrollment estimates, market share estimates were computed as the proportion of the population enrolled in HMOs.

Since the county service areas on which the series are based are quite accurate, it is likely that the series themselves are also quite accurate. Nonetheless, use of any allocation mechanism that produces enrollment estimates will almost certainly lead to measurement error in some cases. Aggregating market shares to the HCSA level should

6. In general, compliance with the survey is quite good. In all five of the years taken together, fewer than ten HMOs (of a total of about 550 per year) failed to indicate their enrollment. Where data was missing, data from subsequent Directories was used. Most HMOs also indicated their service area. In 1990, 459 of 567 HMOs clearly indicated the counties that they served. Response rates improved over time, and by 1994, 566 of 572 HMOs reported their service area clearly. In cases where market area data was not available from the survey, market areas were determined by reference to subsequent Directories and/or telephone contact. 
dampen the effects of any misestimation of market shares that may have occurred at the county level. Although geographically detailed independent data on HMO market share for the whole country for these years are not available, the estimates were compared to estimates for selected sets of metropolitan statistical areas from the GHAA for 1991 (Bergsten and Palsbo 1993) and from Interstudy for 1994 (Interstudy 1994). The estimates performed relatively well in these comparisons. In a few cases, the estimates were found to be at odds with the Interstudy estimates, and where the geographic allocation algorithm appeared to produce erroneous results, we adjusted the estimates to conform to the Interstudy estimates.

On average, systemwide HMO market shares rose from 15 to $21 \%$ between 1990 and 1994 (bottom panel of table 4.2). Within any given year, observed systemwide market shares were fairly widely distributed. For example, in 1994, observed market shares ranged from 0 to $54 \%$. Figure 4.2(a) illustrates the distribution of systemwide HMO market shares across market areas in 1994. Between 1990 and 1994, systemwide HMO market shares rose in most areas. Figure 4.2(b) graphs the distribution of changes in systemwide market share for areas. Systemwide HMO market share changes in the sample range for 1990-94 from $-14 \%$ to $+22 \%$. HMO market share declined in relatively few areas. About $1.0 \%(N=8)$ of the sample had declines of more than $5 \%$. On the other hand, 27\% $(N=219)$ had increases of more than 5\%.

An issue that becomes important as we attempt to disentangle the effects of systemwide and Medicare-specific HMO market share on Medicare expenditures is the extent to which the two measures are correlated. In cross sections for individual years, correlations between the market area estimates range from 0.52 to 0.54 . The correlation between the 1990-94 changes in Medicare and systemwide market share is 0.25 .

\section{Estimation}

\section{Background and Strategy}

Our interest is in estimating the parameters of a function that relates FFS Medicare expenditures in a market to HMO market share in that market. Specifically,

$E_{i}=f\left(S_{i}, M_{i}, X_{i}\right)$, 


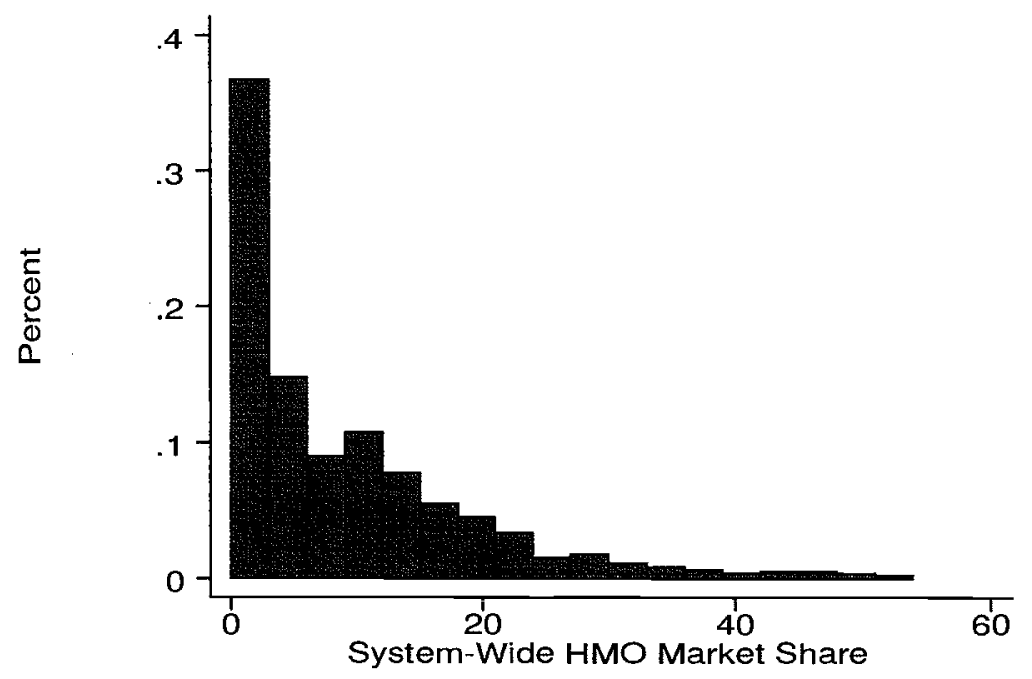

Figure 4.2a

Distribution of 1994 levels of systemwide HMO market share

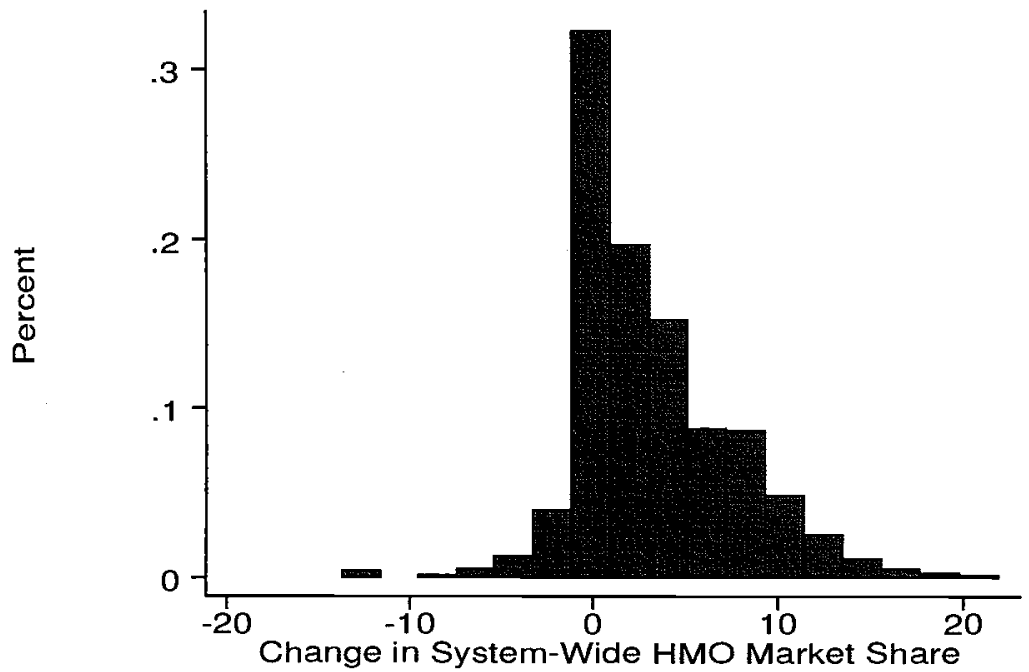

Figure $4.2 \mathrm{~b}$

1990-1994 changes in systemwide HMO market share

Note: Figures are based on 802 HCSAs each. Market areas are defined as HCSAs. 
where $E$ denotes Medicare FFS expenditures, $M$ denotes Medicarespecific HMO activity, $S$ denotes systemwide HMO activity, and $X$ denotes other determinants of Medicare expenditures.

Several issues must be resolved to satisfactorily estimate equation (4.1). First, unobservable variables may be correlated with both market share and expenditures. For example, preferences of patients and providers for conservative care might increase HMO market share and decrease expenditures. Unobserved components of the population's health status may also influence both market share and expenditures. Although we control in the analyses for a number of potential confounding factors that we have been able to identify, we may not have identified all confounders. We attempt to solve this problem by including fixed effects in our models for areas and years. If the unobserved factors are constant within areas over time or are constant within years across areas, inclusion of the fixed effects removes any resulting bias from our estimates. In effect, this approach identifies the effects of HMO market share using changes within areas over time rather than variation in HMO activity across areas within individual years.

Second, HMO market share and expenditures may be simultaneously determined. Forward-looking HMOs may consider both current and expected future expenditures when deciding whether to enter or expand operations in a market. HMOs that can effectively reduce costs or utilization may be most successful in markets where FFS expenditures are high. Previous studies (e.g., Porell and Wallack 1990; Welch 1984; Goldberg and Greenberg 1981) have concluded that overall HMO market share is positively related to health care costs and utilization. Within the context of Medicare, the fact that payments to risk HMOs are dependent on FFS spending levels could also generate simultaneity bias. Areas with high FFS expenditures also have high risk HMO reimbursement rates, which may attract HMOs serving Medicare beneficiaries. If increases in FFS expenditures cause increases in HMO market share, then estimates of HMOs' effect on expenditures that do not account for simultaneity understate any expenditure-reducing effect HMOs may have.

We expect that the use of fixed effects in our analyses alleviates the difficulties associated with simultaneity to a large degree. Relying on changes over time to identify the effect of HMOs removes the bias induced by high expenditure levels causing high HMO market share levels. However, some bias could remain if expected future changes in expenditures prompt changes in market share. Previous work suggests 
that the conclusions drawn from fixed-effects models are broadly consistent with results from cross-sectional models that rely on instrumental variables to remove more fully simultaneity and omitted variables bias (Baker 1997). Further, given that previous work suggests that increases in expenditures should be associated with increases in HMO market share, any expenditure-reducing effects of $\mathrm{HMO}$ market share identified below can be interpreted as conservative to the extent that some simultaneity bias persists. Finally, any simultaneity bias induced through the Medicare risk HMO payment mechanism will influence only our estimates of the effects of Medicare-specific HMO enrollment; controlling for Medicare HMO market share should leave estimates of the effects of systemwide HMO activity unaffected by this source of bias.

Finally, the possibility of biased selection is an issue for estimation. Many studies have found that HMOs and other managed-care organizations receive a favorable selection of beneficiaries (see, among others, Hellinger 1987, 1995; Hill and Brown 1990). Given this evidence, selection bias is expected to associate increases in Medicare HMO market share with increases in FFS expenditures, because moving healthy beneficiaries into Medicare HMOs leaves the Medicare FFS population progressively sicker and therefore more expensive. Geographically detailed data on the characteristics of Medicare FFS and HMO beneficiaries are not available, so we are unable to control directly for the effects of biased selection. However, all of the relevant selection activity should occur with respect to Medicare HMOs, meaning that the Medicare HMO market share variables capture selection bias. Thus, controlling for Medicare HMO market share will leave our estimates of the effects of systemwide HMO market share unaffected by selection, but our estimates of the relationship between Medicare HMO market share and expenditures reflect selection bias as well as any spillover effects.

\section{Results}

We begin by estimating fixed-effects regression models of the form

$$
\begin{aligned}
\log \left(E_{i, t}\right)= & \beta_{0}+\beta_{1} S_{i, t}+\beta_{2} S_{i, t}^{2}+\beta_{3} M_{i, t}+\beta_{4} M_{i, t}{ }^{2}+\beta_{5} \mathbf{X}_{i, t} \\
& +\beta_{6} A_{i}+\beta_{7} Y_{t}+\varepsilon_{i, t},
\end{aligned}
$$

where $\log (E)$ represents the natural logarithm of FFS expenditures per beneficiary, $M$ represents Medicare HMO market share, $S$ represents 
systemwide $\mathrm{HMO}$ market share, $\mathbf{X}$ is a vector of covariates expected to influence expenditures, $A$ is a set of area-specific intercepts, and $Y$ is a set of year-specific intercepts. The errors, $\varepsilon_{i, t}$, are assumed to be independently and identically distributed normal random variables. Subscript $i$ denotes area $i$ and subscript $t$ denotes year $t$.

We estimate these models using current market share data. Most previous studies have used lagged data because $\mathrm{HMO}$ activity may have an effect on FFS expenditures only after a period of time. But because systemwide HMO market share estimates are available only for 1990-94, using current market share allows us to maximize the number of years in our sample. The year-to-year correlation in HMO market share is quite high, and estimation using lagged market shares and dropping 1990 data from the analysis does not significantly affect the estimates.

To capture changes in HMO market share's effect on expenditures as the level of $\mathrm{HMO}$ activity varies, equation (4.2) is quadratic in HMO market share. Previous work has explored various nonlinear functional forms and suggests that a quadratic specification adequately captures the relevant variation. We estimate equation (4.2) using our market area data, excluding the market area that contains Delta, Gunnison, Montrose, Hinsdale, Ouray, and San Miguel counties in Colorado, which experienced an implausibly high drop in systemwide HMO market share between 1990 and 1994, as well as Alaska and Hawaii. The final models use 801 observations per year $(N=4,005)$.

We estimate separate models for Part A and Part B expenditures because differences in the content and reimbursement of ambulatory and hospital care may cause the effect of HMOs to vary. To correct for possible heteroskedasticity arising from variation in enrollments across markets and to maintain consistency with previous work, weighted least-squares regression was used, with Medicare Part A enrollment as the weight.

The control variables include per capita income; the proportions of the population aged 65-74, 75-84, and 85 and over; and the proportions of the over- 65 population that are female, black, and "other race" (i.e., nonwhite and nonblack). To control for broad characteristics of the health care system that may influence expenditures, we include the number of physicians per 1,000 population and the number of hospital beds per 1,000 population. All these variables were obtained from the Census Bureau or from the Area Resource File, a dataset from the U.S. government Bureau of Health Professions that compiles health care 
data from a variety of sources including the AMA, the AHA, and the Census Bureau. The inclusion of area- and year-specific intercepts captures the effects of additional area- and year-specific unobserved or omitted variables.

Table 4.3 shows estimation results. Columns 1 and 4 present coefficients from the main specification. Note that the coefficients have been scaled to represent the effect of a ten-percentage-point change in market share (e.g., moving from $10 \%$ to $20 \%$ market share). To assess the statistical significance of the estimated relationships, $F$ tests of the hypotheses that the linear and quadratic market share terms are jointly equal to zero were conducted separately for systemwide and Medicare market share. In all cases, the results were highly statistically significant.

For most practical purposes, we are concerned with the magnitude of the change in expenditures that would accompany a given change in market share. We estimate the percentage change in expenditures that would be associated with some representative changes in systemwide and Medicare HMO market share using the regression results. Specifically, the ratio of expenditures at system-wide market share $S 2$ to expenditures at system-wide market share $S 1$ can be estimated using:

$$
\begin{aligned}
E_{S 2} / E_{S 1} & =\exp \left(\operatorname{logg} E_{S 2}-\log E_{S 1}\right) \\
& =\exp \left(\hat{\beta}_{1}\left(S_{2}-S_{1}\right)+\hat{\beta}_{2}\left(S_{2}^{2}-S_{1}^{2}\right)\right) .
\end{aligned}
$$

where $\log E_{S 1}$ and $\log E_{S 2}$ are the predicted values of $\log (E)$ at systemwide market shares $S 1$ and $S 2$, respectively. ${ }^{7}$ The quantity $\left(E_{S 2} / E_{S 1}-\right.$ 1) can then be interpreted as the approximate percentage change in expenditures that would be associated with a move from market share $S 1$ to $S 2$. A similar equation can be used for Medicare market share changes, substituting the appropriate estimates from equation (4.2). The top panel of table 4.4 shows the estimated percentage changes in expenditures associated with moving systemwide $\mathrm{HMO}$ market share from 10 to 20,20 to 30 , and 30 to $40 \%$. Estimates of the effect of moving HMO market share higher than 40 percent are not computed because there are relatively few sample points in that range.

Increases in systemwide $\mathrm{HMO}$ activity are associated with decreases in Part A expenditures. In the main specification (column 1), increases

7. Technically, this formula assumes that expenditures are log-normally distributed. Our analyses suggest that the Medicare data do approximately follow this distribution. 


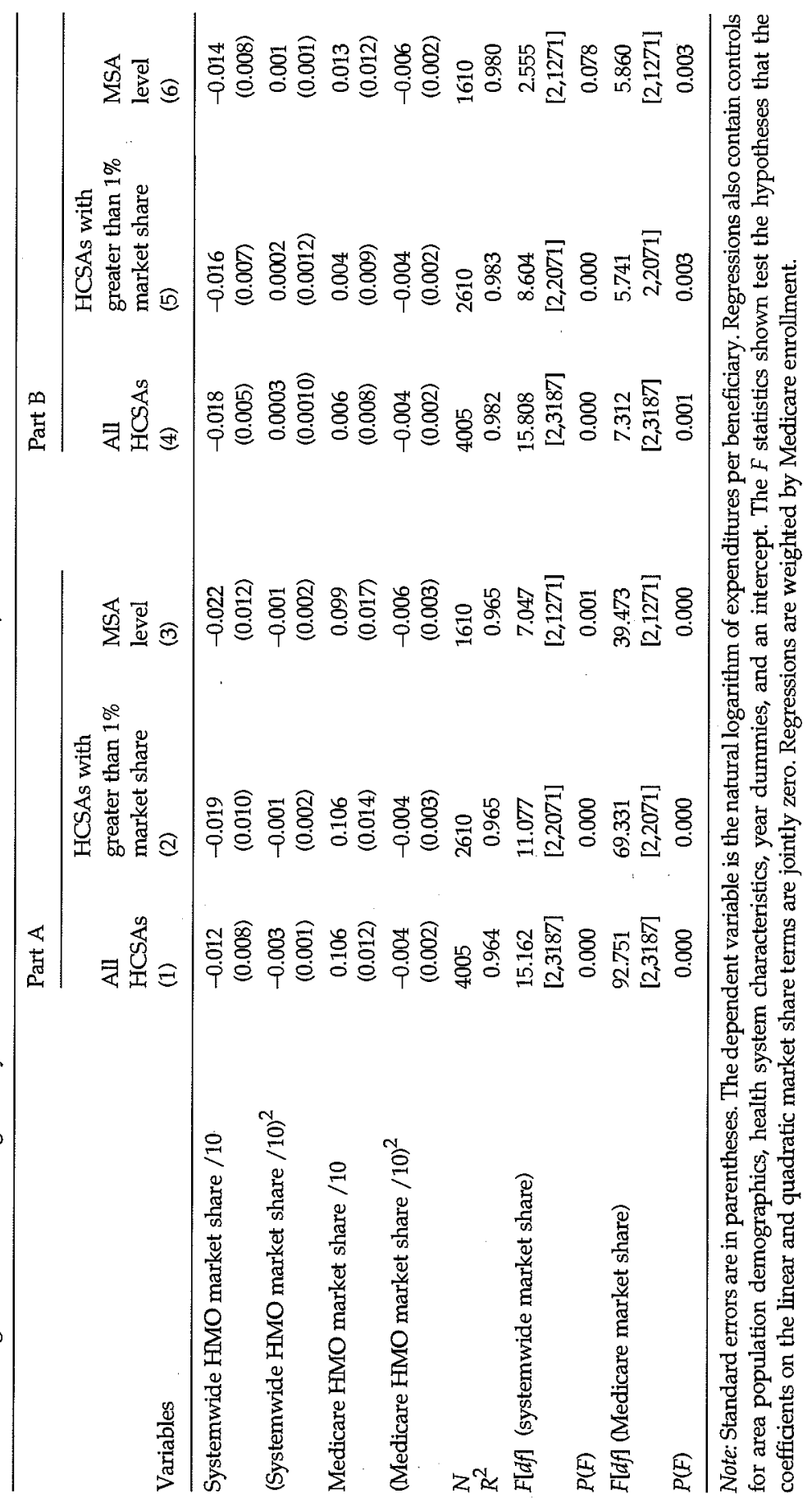




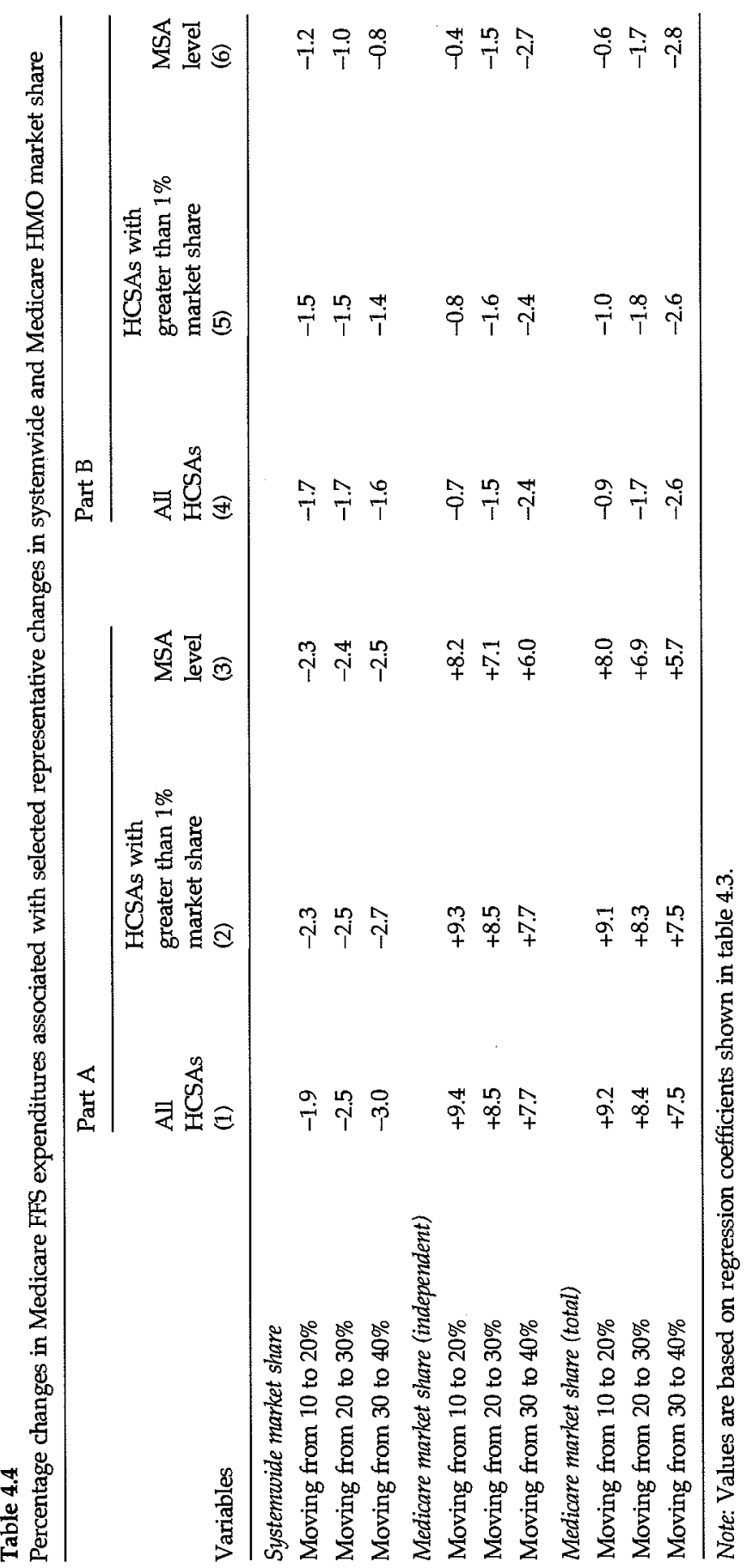


in systemwide HMO market share from 10 to $20 \%$ are associated with $1.9 \%$ reductions in expenditures. Evaluated at the 1994 mean expenditure per beneficiary $(\$ 2,865)$, this corresponds to a decrease of $\$ 54.44$. As HMO market share increases, an increase has a larger effect on expenditures. For example, increases in systemwide HMO market share from 20 to $30 \%$ are associated with $2.5 \%$ reductions in expenditures ( $\$ 71.63$ evaluated at the mean).

Increases in systemwide $\mathrm{HMO}$ market share are also associated with decreases in Part B expenditures (column 4). Increases in systemwide market share from 10 to $20 \%$ are associated with $1.7 \%$ decreases in expenditures. At mean 1994 expenditure levels $(\$ 1,539)$, this would correspond to a decrease of $\$ 26.16$. Increases in HMO market share have weaker effects as HMO market share rises, but only to a limited degree. Increases in systemwide HMO market share from 20 to 30 or from 30 to $40 \%$ are associated with decreases of 1.7 and $1.6 \%$ percent, respectively, in Part $B$ expenditures.

These findings are consistent with the hypothesis that systemwide HMO activity can influence the health care system in ways that affect expenditures for all patients. The evidence presented here is stronger than that found in previous studies because we have accounted for selection bias by including Medicare HMO market share as a control variable and for unobserved heterogeneity across markets by including market fixed effects.

Interpreting the results in tables 4.3 and 4.4 for Medicare-specific market share is less straightforward because the systemwide HMO market share variables include Medicare HMO market share along with non-Medicare $\mathrm{HMO}$ market share. To investigate the effect of a change in Medicare HMO market share independent of any effects of systemwide market share, we could use the regression coefficients $\beta_{3}$ and $\beta_{4}$ directly. But to assess fully the effects of a change in Medicare HMO market share, we must account for the effects of Medicare market share alone (through $\beta_{3}$ and $\beta_{4}$ ) as well as the effects of Medicare market share that occur through systemwide market share (captured in $\beta_{1}$ and $\beta_{2}$ ). Appendix A presents the equations necessary to do this. Table 4.4 summarizes the implied changes in expenditures associated with representative changes in market share using just the Medicare market share coefficients (the "independent" effect) and the implied changes in expenditures when both Medicare and systemwide effects are included (the "total" effect). 
Increases in market share are associated with relatively large increases in Part A expenditures-independently, increases in Medicare HMO market share from 10 to $20 \%$ are associated with $9.4 \%$ increases in expenditures. Increases in market share are independently associated with decreases in Part B expenditures for market shares above about $7 \%$. Increases in market share from 10 to $20 \%$ are associated with decreases of $0.7 \%$. In both cases, the total effects are quite similar.

Drawing conclusions about the existence and magnitude of Medicare-specific spillover effects from these results is complicated by the fact that the coefficients capture the effects of biased selection and simultaneity, which are expected to associate increases in HMO market share with increases in expenditures, along with any expenditurereducing spillovers. Thus, the results for Part A suggest that any spillover effects associated with Medicare HMO market share are much smaller than the effects of selection bias and simultaneity. For Part B, the results imply that there may be spillover effects large enough to offset the effects of selection bias and simultaneity.

To examine the robustness of the results, two alternate specifications of the basic equation were estimated. First, because many areas had very low Medicare HMO market shares, equation (4.2) was reestimated using only data from 522 HCSA market areas in which market share exceeded 1\% in all years examined (columns 2 and 5 of tables 4.3 and 4.4). Second, equation (4.2) was reestimated using data at the metropolitan statistical area (MSA) level. MSAs are an alternative to HCSAs as a market definition and have been used by other authors, although they do not permit the inclusion of nonmetropolitan areas (columns 3 and 6 of tables 4.3 and 4.4). In both cases, the results are consistent with those reported above.

In addition to the models shown in tables 4.3 and 4.4 , we tested several other specifications to examine the robustness of the results reported. We estimated equation (4.2) using unweighted least-squares regression, using lagged rather than current HMO market shares and dropping 1990, and excluding the number of short-term acute care hospital beds per 1,000 population and the number of physicians per 1,000 population in the area, because HMO market share may influence these variables, which could cause us to understate $\mathrm{HMO}$ activity's true effect. In all cases, the results were similar to the results initially obtained. 


\section{Comparison to Earlier Work}

Four previous studies have examined the relationship between Medicare HMO market share and Medicare FFS expenditures. Table 4.5 summarizes the percentage changes in Medicare FFS expenditures estimated in these studies to accompany ten-percentage-point increases in Medicare market share. For Part A, previous studies suggested that expenditure decreases of 1.3 to $6.6 \%$ would accompany such increases, with most estimates toward the higher end of that range. For Part B, estimates ranged from 1.4 to $12.1 \%$ decreases. The results we present suggest that increases in Medicare HMO market share are associated with increases in Part A spending. The estimated declines in Part B spending that we report are generally much smaller than those reported in previous work.

Previous results and the results presented here could differ because our data is newer or because the model specified here differs from specifications in earlier studies (e.g., because we include both systemwide and Medicare market share). To present some information about

\section{Table 4.5}

Main estimates from previous studies of the percentage reductions in Medicare FFS spending accompanying ten-percentage-point increases in Medicare HMO market share

Effect of a ten-percentage-point increase in Medicare HMO market share on

\begin{tabular}{lllll} 
& $\begin{array}{l}\text { Years } \\
\text { Study }\end{array}$ & $\begin{array}{l}\text { Part A } \\
\text { examined }\end{array}$ & $\begin{array}{l}\text { Part B } \\
\text { expenditures }\end{array}$ & $\begin{array}{l}\text { All } \\
\text { expenditures }\end{array}$ \\
\hline Baker 1997 & $1986-90$ & $-4.5,-6.6^{\mathrm{a}}$ & $-4.1,-5.6^{\mathrm{a}}$ & - \\
Rodgers and Smith 1995 & $1988-92$ & $-4.8^{\mathrm{b}}$ & $-12.1^{\mathrm{b}}$ & $-7.9^{\mathrm{b}}$ \\
Welch 1994 & $1986-87$ & $-1.3^{\mathrm{c}}$ & $-1.4^{\mathrm{c}}$ & $-1.2^{\mathrm{c}}$ \\
Clement, Gleason, and & $1985-88$ & $-6^{\mathrm{d}}$ & $-4^{\mathrm{d}}$ & $-5^{\mathrm{d}}$ \\
Brown 1992 & & & &
\end{tabular}

\footnotetext{
${ }^{a}$ Baker (1997) estimated a nonlinear specification. Results shown here are for moves from 10 to 20 and from 20 to $30 \%$ market share, respectively.

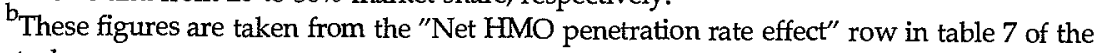
study.

'These are Welch's short-run estimates. He argues that the long-run effects of a change in market share may be much larger. Only the estimate for Part B expenditures is statistically significant at the $p=0.05$ level. (The estimate for all expenditures is significant at the $p=0.10$ level.)

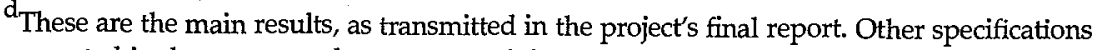
presented in the paper produce a range of similar results.
} 
these two alternatives, we have estimated two additional models. First, we replicated the specification used above eliminating the systemwide HMO market share variables. Columns 1 and 3 of table 4.6 show these results. Here, the implied increases in Part A expenditures are somewhat smaller than those observed with systemwide HMO market share included (cf. table 4.4). For Part B expenditures, the results suggest larger declines in expenditures. Together these results suggest that when systemwide HMO market share is omitted from the specification, the Medicare HMO market share variables capture some of its expenditure-reducing effect and may overstate the size of associated cost decreases or understate the size of associated cost increases.

Table 4.6

Fixed-effects regression results from models with only Medicare HMO market share, 1990-1994

\begin{tabular}{|c|c|c|c|c|}
\hline \multirow[b]{2}{*}{ Variables } & \multicolumn{2}{|l|}{ Part A } & \multicolumn{2}{|l|}{ Part B } \\
\hline & $\begin{array}{l}\text { Replicate } \\
\text { table } 4.3 \\
\text { (1) }\end{array}$ & $\begin{array}{l}\text { Replicate } \\
\text { Baker } 1997 \\
\text { (2) }\end{array}$ & $\begin{array}{l}\text { Replicate } \\
\text { table } 4.3 \\
\text { (3) }\end{array}$ & $\begin{array}{l}\text { Replicate } \\
\text { Baker 199? } \\
\text { (4) }\end{array}$ \\
\hline \multicolumn{5}{|l|}{ Regression coefficients } \\
\hline $\begin{array}{l}\text { Medicare HMO market share } \\
/ 10\end{array}$ & $\begin{array}{c}0.096 \\
(0.012)\end{array}$ & $\begin{array}{c}0.064 \\
(0.008)\end{array}$ & $\begin{array}{c}-0.0002 \\
(0.0080)\end{array}$ & $\begin{array}{l}-0.037 \\
(0.005)\end{array}$ \\
\hline $\begin{array}{l}\text { (Medicare HMO market share } \\
/ 10)^{2}\end{array}$ & $\begin{array}{c}-0.004 \\
(0.002)\end{array}$ & $\begin{array}{c}-0.003 \\
(0.002)\end{array}$ & $\begin{array}{c}-0.004 \\
(0.002)\end{array}$ & $\begin{array}{c}-0.001 \\
(0.001)\end{array}$ \\
\hline$N$ & 4005 & 15370 & 4005 & 15370 \\
\hline$R^{2}$ & 0.964 & 0.952 & 0.982 & 0.976 \\
\hline$F[d f]$ (market share) & $\begin{array}{l}79.84 \\
{[2,3189]}\end{array}$ & $\begin{array}{l}78.99 \\
{[2,12283]}\end{array}$ & $\begin{array}{l}12.22 \\
{[2,3189]}\end{array}$ & $\begin{array}{l}101.63 \\
{[2,12283]}\end{array}$ \\
\hline$P(F)$ & 0.000 & 0.000 & 0.000 & 0.000 \\
\hline
\end{tabular}

Implied percentage changes in expenditures from representative changes in HMO market share

$\begin{array}{lllll}\text { Moving from } 10 \text { to } 20 \% & +8.3 & +5.4 & -1.2 & -3.8 \\ \text { Moving from } 20 \text { to } 30 \% & +7.4 & +4.8 & -2.0 & -4.0 \\ \text { Moving from } 30 \text { to } 40 \% & +6.6 & +4.1 & -2.9 & -4.1\end{array}$

Note: Standard errors are in parentheses. The dependent variable is the natural logarithm of expenditures per beneficiary. Columns 1 and 3 replicate the specification used in table 4.3, except that systemwide HMO market share is excluded. Columns 2 and 4 replicate the specification used in Baker 1997. In columns 2 and 4, Medicare HMO market share is lagged one year. Regressions also contain controls for area population demographics, year dummies, and an intercept. Regressions in columns 1 and 3 also include physicians and hospital beds per capita. The $F$ statistics shown test the hypotheses that the coefficients on the linear and quadratic market share terms are jointly zero. Regressions are weighted by Medicare enrollment. 
To investigate the effect of using newer data, we have also replicated the specification used in Baker 1997, which included only Medicare HMO market share and was originally run using data from 1986-90, using our data from 1990-94. This specification is similar to that used above but differs in three ways: The models are estimated at the county, rather than the HCSA, level; ${ }^{8}$ lagged HMO market share is used instead of current; and the variables measuring the number of physicians and hospital beds per capita are not included. Columns 2 and 4 of table 4.6 present results. Here, increases in Medicare market share from 10 to $20 \%$ are associated with $5.4 \%$ increases in Part A expenditures. Results using data from 1986-90 showed that Part A expenditures fell by $4.5 \%$ for the same increase in market share. Comparing these results suggests that the relationship between HMO market share and expenditures may have changed over time and that the differences between the findings reported above and those in previous studies may stem both from changes in the specifications and changes over time. For Part B expenditures, 1990-94 data imply that increases in HMO market share from 10 to $20 \%$ are associated with declines of $3.8 \%$ percent, whereas 1986-90 data implied that increases in market share from 10 to $20 \%$ were associated with $4.0 \%$ decreases. These results suggest that, for Part $\mathrm{B}$, the differences between the findings here and the earlier findings are more closely related to changes in the specification and the inclusion of systemwide market share than to changes over time.

\section{An Alternate Specification}

The models described above rely on changes in HMO market share and expenditures over time to identify the effects of HMO market share. Although this approach has powerful statistical properties, allows us to incorporate five years of data, and is consistent with previous studies, it does not incorporate the baseline levels of expenditures and HMO market share. Thus, it does not permit us to investigate the possibility that initial levels of $\mathrm{HMO}$ activity may influence the subsequent growth rate of expenditures. If areas with initially high levels of HMO market shares had slower expenditure growth, for

8. We exclude from the analyses counties with fewer than 50 beneficiaries in any of the years. The final sample included 3,074 counties per year $(N=15,370)$. 
example, fixed-effects models that essentially difference out the baseline market share levels would not capture this effect. Of particular concern is the possibility that initial levels of HMO market share may also be associated with the subsequent growth rate of HMO market share. ${ }^{9}$ If initial HMO market share is associated with both expenditure growth and HMO market share growth, then fixed-effects models may lead to inaccurate estimates of the effects of changes in HMO activity.

To account for both initial levels of HMO activity and changes over time, we estimate first-differenced models of the form

$$
\begin{aligned}
\log \left(E_{i, 94}\right)-\log \left(E_{i, 90}\right)= & \beta_{0}+\beta_{1} S_{i, 90}+\beta_{2}\left(S_{i, 94}-S_{i, 90}\right)+\beta_{3} M_{i, 90} \\
& +\beta_{4}\left(M_{i, 94}-M_{i, 90}\right)+\beta_{5} Q 1_{i, 90}+\beta_{6} Q 4_{i, 90} \\
& +\beta_{7} \mathbf{X}_{i, 90}+\beta_{8}\left(\mathbf{X}_{i, 94}-\mathbf{X}_{i, 90}\right)+\eta_{i}
\end{aligned}
$$

That is, this specification models the difference in log expenditures between 1990 and 1994, which is approximately equal to the percentage change in expenditures over that time, as a function of the initial levels of HMO market share and the 1990-94 changes in market share. We include in $\mathbf{X}$ the same set of covariates as above to control for population and health system characteristics, and we add the percentage of the population in each market that lives in an urban area to capture urban-rural differences.

Equation (4.4) is estimated using the market area (HCSA) data. As above, we exclude Alaska, Hawaii, and the Colorado HCSA that appears to have inaccurate systemwide HMO market share data. We do not include quadratic terms in the market shares, because this makes the equation unwieldy and does not add substantially to the conclusions. We weight the regressions using the 1990 Medicare HMO enrollment in each market area.

A potential difficulty with estimating equation (4.4) is that in areas with particularly high or low expenditures in a given year, expenditures may regress to the mean over time. For example, if an area has high expenditures in one year because of particularly bad health outcomes in its population, it is likely to have lower health expenditures in subsequent years because the health outcomes the area population experiences are likely to fall more near the mean. ${ }^{10}$ If managed-care

9. The observed (weighted) correlation between the 1990 systemwide market share and the 1990-94 change is 0.23; for Medicare market share, the correlation is 0.41 .

10. The observed (weighted) correlations between the log of mean 1990 expenditures and the 1990-94 changes in log expenditures are -0.36 for Part A and -0.64 for Part B. 
organizations disproportionately locate in high-expenditure areas, then the resulting association between HMO market share and subsequent regression to the mean in expenditures could produce biased estimates of HMO's effects. The variables $Q 1$ and $Q 4$ in equation (4.4) are dummy variables indicating whether the market area was in the highest or lowest expenditure quartile in 1990 and are intended to capture the effects of regression to the mean:

Table 4.7 presents estimation results. The models in columns 1 and 3 do not control for the initial level of expenditures; the models in columns 2 and 4 do. For Part A, the coefficients on the initial level of systemwide market share are statistically insignificant. However, growth in systemwide market share over time is associated with lower expenditure growth. With controls for initial expenditure levels included, 10-percentage-point increases in systemwide market share are associated with 4.3-percentage-point reductions in expenditure growth rates. At least in this context, changes in HMO activity are more important than the initial level in determining spending growth.

The story is reversed for Medicare HMO market share. Although the initial level of Medicare market share is not significant, the results imply that 10-percentage-point increases in Medicare market share are associated with 4.5-percentage-point increases in the spending growth rate. These results, like those presented above, suggest that selection and simultaneity bias effects may outweigh any Medicare-specific spillovers.

For Part B, the initial level of systemwide HMO market share is again insignificant, but increases in market share over time are associated with decreases in expenditure growth rates. With the controls for the initial level of spending included, a 10-percentage-point increase in systemwide market share would reduce the expenditure growth rate by 1.1 percentage points. Both the initial level of Medicare HMO market share and the 1990-94 change in Medicare market share are associated with decreases in expenditures. Ten-percentage-point increases in the initial market share level are associated with 2.0-percentage-point reductions in expenditure growth, and 10-percentage-point increases over time are associated with 2.8-percentage-point reductions, suggesting spillover effects directly associated with Medicare $\mathrm{HMO}$ market share may be strong enough to overcome positive effects of selection and simultaneity bias. 


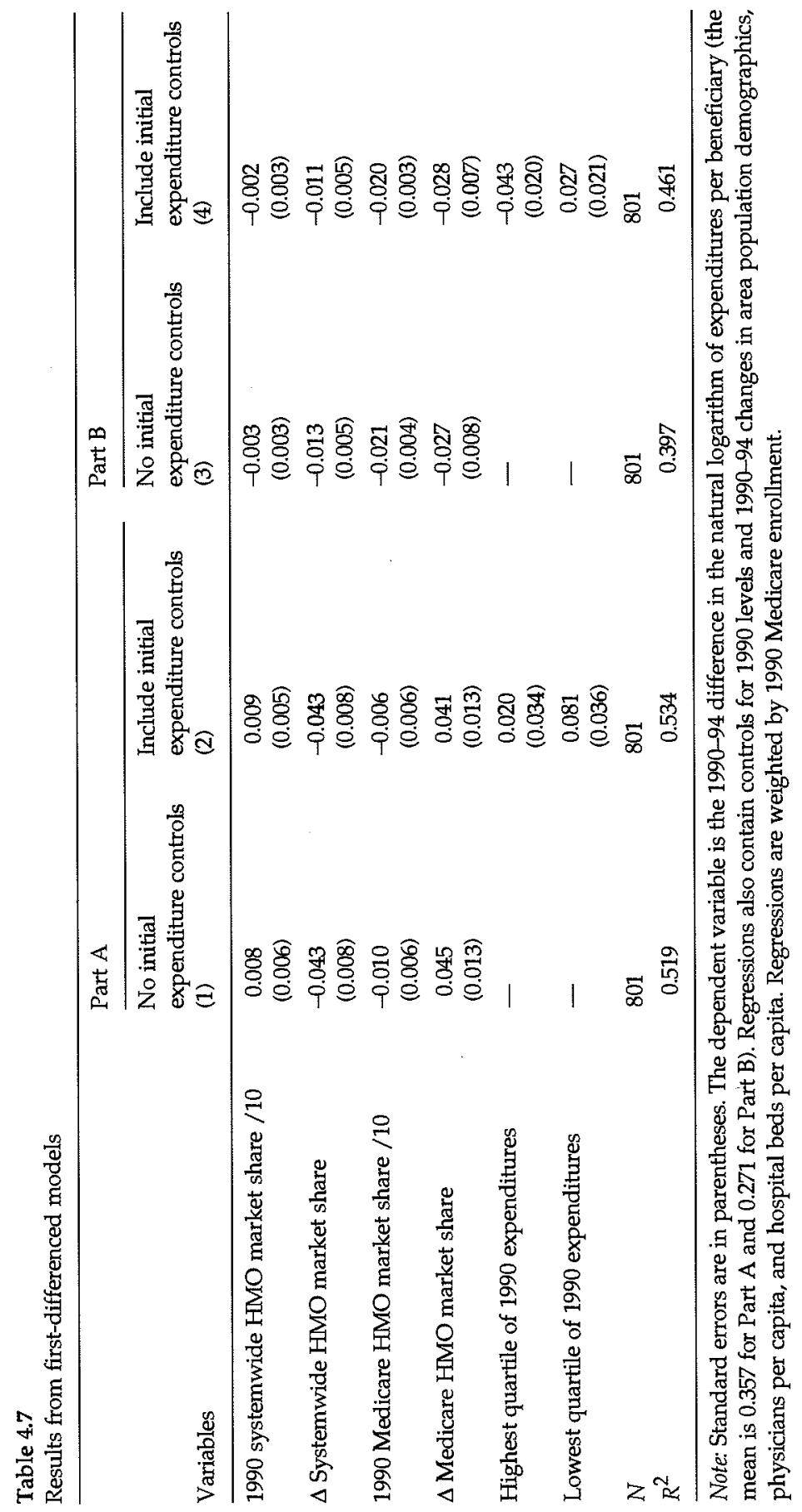




\section{Discussion}

We draw two sets of conclusions from these results. First, increases in systemwide HMO market share reduce expenditures for the care of Medicare FFS beneficiaries, a population that should be well-insulated from the direct effects of managed care. Increases in systemwide market share from 10 to $20 \%$ were associated with decreases of 1.9 to $2.3 \%$ in Part A expenditures and 1.2 to $1.7 \%$ in Part B expenditures. This is consistent with the hypothesis that managed care can have significant spillover effects that broadly influence the entire health care system's structure and functioning.

Given Medicare's structure, we believe that these findings largely reflect spillover effects that occur through the availability and use of health care services. For example, Baker and Wheeler (1997) report that increases in HMO market share are associated with a decline in the systemwide availability of MRI equipment. Cutler and Sheiner (1997) also report that areas with high levels of HMO activity may have reduced technology availability. Reductions in the general availability of health care equipment and technologies may translate into reduced systemwide use, providing a mechanism for reductions in spending. Increases in HMO market share may also lead to changes in health care providers' behavior independent of any changes in the availability of services.

By extrapolation, these results believe that managed care may also influence the care provided to non-managed-care patients outside of Medicare. In fact, because the Medicare FFS program is not subject to the competition that pervades the non-Medicare sector of the health care market, and because spillover effects that occur through changes in price are not likely to be observed in Medicare data, spillover effects in other sectors of the health care market might even be larger.

From a policy standpoint, these results suggest that managed care's systemwide effects should be considered when assessing the ongoing shift toward managed care and that the interests of non-managed-care patients should be considered when policies that would influence managed-care growth are evaluated. In addition, scrutiny should be given to studies that examine differences between utilization and outcomes of managed-care and non-managed-care patients, because managed care may induce changes in these variables for nonmanaged-care patients as well. 
Second, spillover effects associated directly with Medicare HMO market share are likely to be small. Updating previous work revealed that increases in Medicare HMO market share are associated with increases in Part A expenditures, the opposite of previous findings. Because the Medicare HMO market share coefficients capture the effects of selection bias as well as any spillover effects, these findings suggest that biased selection's expenditure-increasing effects are substantially larger than any expenditure-decreasing spillover effects.

Our more recent results may differ from previous results for a number of reasons. The importance of Medicare-specific spillovers for Part A expenditures may have diminished over time to the point where they are no longer a strong force. As a second possibility, selection bias may have become stronger over time. A third possibility stems from the relationship between Medicare and systemwide HMO market share. If Medicare market share was better correlated with systemwide HMO market share in the 1980s than in the 1990s, then the Medicare HMO market share coefficients in the earlier studies may have reflected systemwide spillover effects to a greater degree. In the presence of expenditure-reducing systemwide spillovers, this could have caused studies using Medicare market share to show an expenditure-decreasing effect in earlier years when in fact the real action was systemwide.

It is difficult to evaluate the relative strengths of these possible explanations, and further study of them will be necessary. We did explore the possibility that the correlation between Medicare and systemwide market share has changed over time. Because geographically detailed data on systemwide market shares are not available for the 1980s, we used state-level data to examine the correlation between the 1986-90 change in Medicare and systemwide market share, and compared it to the correlation between the 1990-94 changes in Medicare and systemwide market share. For the earlier time period, the correlation is 0.27 , whereas for the latter time period, the correlation is 0.20 . Although neither of these correlations is very high, they do leave open the possibility that some of the difference in the results is due to a reduction in the extent to which Medicare HMO market share proxies systemwide market share.

Regardless of the cause, these findings suggest that conclusions about Medicare-specific spillovers for Part A expenditures drawn from previous studies that used Medicare-specific HMO market share may 
substantially overstate actual spillovers. This finding does not prove that Medicare market share has no associated spillover effect, only that any spillover effect that is present is smaller than other expenditureincreasing effects associated with increasing Medicare market share (e.g., selection bias).

For Part B expenditures, we find evidence consistent with the presence of spillover effects that are associated with Medicare market share. But holding systemwide market share constant, the magnitude of these results is much smaller than the effect of Medicare market share observed in models that do not include systemwide market share. Our results imply that increases in market share may be associated with decreases in expenditures on the order of 1 to $2 \%$ after controlling for systemwide market share, whereas earlier models that did not control for systemwide market share reported results generally at least twice as large.

The existence of a spillover effect that stems directly from Medicare HMO market share is interesting, given the relative weakness of the financial incentives within Medicare. Learning spillovers or other phenomena may occur between physicians treating the elderly that are confined to the Medicare world. Further investigation of the source of this finding will be needed.

Taken broadly, these results suggest that managed care transforms the functioning of the entire health care system. But in the context of Medicare reform discussions, these results suggest that caution should be exercised before relying on spillover effects to generate savings from increases in Medicare HMO market share. Although our results do not rule out the possibility of spillovers directly associated with increasing Medicare market share, they suggest that the effect may be much smaller than has been previously thought. The presence of a systemwide spillover effect, to which changes in Medicare HMO market share could contribute, does suggest that Medicare HMO market share can have spillover effects but that the impact of a change in Medicare market share may be limited by the role of Medicare HMO activity within the broader scope of systemwide HMO activity.

\section{Appendix A: Computing the Effect of a Change in Medicare HMO Market Share for Equation (4.2).}

Let $P_{m}$ and $P_{o}$ denote the number of people in an area who are in Medicare and not in Medicare, respectively, and $E_{m}$ and $E_{o}$ denote 
HMO enrollment among Medicare beneficiaries and the rest of the population, respectively. Then, we can write $M=\left(E_{m} / P_{m}\right)$ and $S=\left(E_{m}+E_{o}\right) /\left(P_{m}+P_{0}\right)$. The regression coefficients $\beta_{1}$ and $\beta_{2}$ capture part of the effect of increasing Medicare HMO market share. To separate out the effect of Medicare HMO market share, we write out the relevant parts of equation (4.2), inserting the enrollment and population variables:

$\log \left(E_{i, t}\right)=\beta_{1} \frac{E_{m}+E_{o}}{P_{m}+P_{o}}+\beta_{2}\left(\frac{E_{m}+E_{o}}{P_{m}+P_{o}}\right)^{2}+\beta_{3} \frac{E_{m}}{P_{m}}+\beta_{4}\left(\frac{E_{m}}{P_{m}}\right)^{2}$.

This can be rewritten as:

$\log \left(E_{i, t}\right)=\delta_{1} \frac{E_{m}}{P_{m}}+\delta_{2}\left(\frac{E_{m}}{P_{m}}\right)^{2}+\beta_{1} \frac{E_{o}}{P_{m}+P_{o}}+\beta_{2}\left(\frac{E_{o}}{P_{m}+P_{o}}\right)^{2}$

where

$\delta_{1}=\frac{P_{m}}{P_{m}+P_{o}} \beta_{1}+\beta_{3}$

and

$\delta_{2}=\left(\frac{P_{m}}{P_{m}+P_{0}}\right)^{2} \beta_{2}+\beta_{4}$.

That is, $\delta_{1}$ and $\delta_{2}$ determine the effect of an increase in Medicare market share, and they incorporate $\beta_{3}$ and $\beta_{4}$ along with scaled components reflecting the effects of systemwide market share $\beta_{1}$ and $\beta_{2}$, where the scaling factor is the proportion of the population in Medicare. In 1994, approximately $12.4 \%$ of the population was enrolled in Medicare, and the implementations of these formulas used in the paper use this value. Using $\delta_{1}$ and $\delta_{2}$ in place of $\beta_{3}$ and $\beta_{4}$, estimated percent changes in expenditures associated with given changes in Medicare HMO market share can be obtained using equation (4.3) in the text.

\section{References}

Baker, L. C. 1997. "The Effect of HMOs on Fee-for-Service Health Care Expenditures: Evidence from Medicare." Journal of Health Economics 16:453-82.

Baker, L. C. 1995. "County-Level Measures of HMO Enrollment and Market share." Stanford University, Stanford, CA. Mimeographed.

Baker, L. C. 1994. "Does Competition from HMOs Affect Fee-for-Service Physicians?" Working paper no. 4920, National Bureau of Economic Research, Cambridge, MA. 
Baker, L. C., and M. L. Brown. 1997. "The Effect of Managed Care on Health Care Providers: Evidence from Mammography." Working paper no. 5987, National Bureau of Economic Research, Cambridge, MA.

Baker, L. C., and K. S. Corts. 1996. "HMO Penetration and the Cost of Health Care: Market Discipline or Market Segmentation?" American Economic Review 86:390-4.

Baker, L. C., and S. W. Wheeler. 1997. "HMOs and the Availability and Use of Magnetic Resonance Imaging." Stanford University, Stanford, CA. Manuscript.

Bergsten, C. D., and S. E. Palsbo. 1993. HMO Market Penetration in the 54 Largest Metropolitan Statistical Areas, 1991. Washington, DC: Group Health Association of America, April.

Chernew, M. 1995. "The Impact of Non-IPA HMOs on the Number of Hospitals and Hospital Capacity." Inquiry 32:143-54.

Clement, D. G., P. M. Gleason, and R. S. Brown. 1992. The Effects of Risk Contract HMO Market Penetration on Medicare Fee-for-Service Costs. Final report prepared for the Health Care Financing Administration, U.S. Department of Health and Human Services, Washington, DC, by Williamson Institute for Health Studies, Departinent of Health Administration, Medical College of Virginia, Richmond, VA, and Mathematica Policy Research, Princeton, NJ.

Cromwell, J., and J. B. Mitchell. 1986. "Physician-Induced Demand for Surgery." Journal of Health Economics 5:293-313.

Cutler, D. M., and L. Sheiner. 1997. "Managed Care and the Growth of Medical Expenditures." Harvard University, Cambridge, MA. Manuscript.

Dowd, B. E. 1987. "HMOs and Twin Cities Admission Rates." Health Services Research 21 (part I):177-88.

Feldman, R., B. E. Dowd, D. McCann, and A. Johnson. 1986. "The Competitive Impact of Health Maintenance Organizations on Hospital Finances: An Exploratory Study." Journal of Health Politics, Policy, and Law 10:675:98.

Frank, R. G., and W. P. Welch. 1985. "The Competitive Effects of HMOs: A Review of the Evidence." Inquiry 22:148-61.

Goldberg, L. G., and W. Greenberg. 1981. "The Determinants of HMO Enrollment and Growth." Health Services Research 16:421-38.

Goldberg, L. G., and W. Greenberg. 1979. "The Competitive Response of Blue Cross and Blue Shield to the Growth of Health Maintenance Organizations in Northern California and Hawaii." Medical Care 17:1019-28.

Group Health Association of America. 1990-1995, annually. National Directory of HMOs. Washington, DC: GHAA.

Hammonds, K. H. 1997. "Medicare Gets an Umbrella for an Avalanche." Business Week, 2 June, p. 44.

Hellinger, F. J. 1995. "Selection Bias in HMOs and PPOs: A Review of the Evidence." Inquiry 32:135-42.

Hellinger, F. J. 1987. "Selection Bias in Health Maintenance Organizations: Analysis of Recent Evidence." Health Care Financing Review 9:55-63. 
Hill, J. W., and R. S. Brown. 1990. Biased Selection in the TEFRA HMO/CMP Program. Report prepared for the U.S. Department of Health and Human Services, Health Care Financing Administration, Baltimore, MD, by Mathematica Policy Research, Princeton, NJ. Contract no. 500-88-0006.

Interstudy. Competitive Edge. Excelsior, MN: Interstudy.

Luft, H. S., and R. H. Miller. 1988. "Patient Selection in a Competitive Health Care System." Health Affairs 7:97-111.

Luft, H. S., S. C. Maerki, and J. B. Travner 1986. "The competitive effects of health maintenance organizations: Another look at the evidence from Hawaii, Rochester, and Minneapolis/St. Paul," Journal of Health Politics, Policy, and Law 10:625-658.

Makuc, D. M., B. Haglund, D. D. Ingram, J. C. Kleinman, and J. J. Feldman. 1991. Vital and Health Statistics-Health Care Service Areas for the United States. Washington, DC: National Center for Health Statistics.

McClellan, M. B. 1997. "Hospital Reimbursement Incentives: An Empirical Analysis." Journal of Economics and Management Strategy 6:91-128.

McLaughlin, C. G. 1988. "The effect of HMOs on overall hospital expenses: Is Anything Left after Correcting for Simultaneity and Selectivity?". Health Services Research 23:421-41.

McLaughlin, C. G. 1987. HMO Growth and Hospital Expenses and Use: A Simultaneous-Equation Approach. Health Services Research 22:183-205.

Mitchell, J. B., G. Wedig, and J. Cromwell. 1989. "The Medicare Physician Fee Freeze: What Really Happened?" Health Affairs 8:21-33.

Noether, M. 1988. "Competition Among Hospitals." Journal of Health Economics 7:259-84.

Phelps, C. 1992. "Diffusion of information in medical care." Journal of Economic Perspectives 6:23-42.

Porell, F. W., and S. S. Wallack. 1990. "Medicare Risk Contracting: Determinants of Market Entry." Health Care Financing Review 12:75-85.

Robinson, J. C. 1996. "Decline in Hospital Utilization and Cost Inflation under Managed Care in California." Journal of the American Medical Association 276(13):1060-4.

Robinson, J. C. 1991. "HMO Market Penetration and Hospital Cost Inflation in California." Journal of the American Medical Association 266:2719-23.

Rodgers, J., and K. E. Smith. 1995. Do Medicare HMOs reduce fee-for-service costs? Health Policy Economics Group report. Washington DC: Price Waterhouse LLP.

Welch, W. P. 1994. "HMO Market Share and Its Effect on Local Medicare Costs. In HMOs and the Elderly, ed. H. S. Luft, 231-49. Ann Arbor, MI: Health Administration Press. 
